MEDICINE AND THE LAW

\title{
Is the mass circumcision drive in KwaZulu-Natal involving neonates and children less than 16 years of age legal? What should doctors do?
}

\author{
D J McQuoid-Mason
}

David McQuoid-Mason is Professor of Law at the Centre for Socio-Legal Studies, University of KwaZulu-Natal, Durban, and publishes and teaches medical law.

Corresponding author: D McQuoid-Mason (mcquoidm@ukzn.ac.za)

As a result of the revival of male circumcision among Zulu males as a cultural practice and an attempt to reduce the incidence of HIV infection, the KwaZulu-Natal government has implemented a programme of mass circumcision of Zulu males. The question arises whether the implementation of such a programme on neonates and children under 16 years of age is legal in terms of the Constitution and the Children's Act. The answer hinges on whether the circumcision is done as a cultural practice or for medical reasons. Doctors are provided with guidance as to what they should do when faced with neonates or males under 16 years of age being presented for circumcision.

S Afr Med J 2013;103(5):283-284. DOI:10.7196/SAMJ.6701

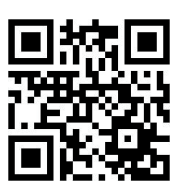

As a result of King Goodwill Zwelithini kaBhekuzulu reviving male circumcision among Zulu males as a cultural practice and to help stem the tide of HIV infection, ${ }^{[1]}$ the KwaZulu-Natal (KZN) government has implemented a programme of mass circumcision of Zulu males. ${ }^{[2]}$ In terms of the Constitution ${ }^{[3]}$ and the Children's Act ${ }^{[4]}$ is the implementation of such a programme, when applied to neonates and children under 16 years of age, legal? The answer depends on whether the circumcision is undertaken as a cultural practice or for medical reasons.

Voluntary circumcision of males over 16 years of age for cultural purposes is legal; however, involuntary circumcision for such reasons is illegal. ${ }^{[5]}$ Doctors need guidance when dealing with males under 16 years of age.

\section{The Constitution and children's rights}

The Constitution provides that children have the right to basic healthcare services and to be protected from maltreatment, neglect, abuse or degradation. ${ }^{[6]}$ It also provides that 'the child's best interests are of paramount importance in every matter concerning the child. ${ }^{[7]}$ By circumcising neonates and children under 16 years of age, is the KZN government implementing their right to basic healthcare services? Does compelled circumcision of such neonates and children amount to their maltreatment, neglect, abuse or degradation? Furthermore, is such compulsory circumcision in the best interests of these neonates and children?

\section{The Children's Act and circumcision of persons under 16 years of age}

The Children's Act specifically mentions when circumcision of children below the age of 16 years may occur. The Act states that circumcision of male children under the age of 16 is prohibited, except when:

- circumcision is performed for religious purposes in accordance with the practice of the religion concerned and in the manner prescribed; or
- circumcision is performed for medical reasons on the recommendation of a medical practitioner. ${ }^{[8]}$

Any person who contravenes the abovementioned provisions of the Act may be liable to a fine or imprisonment not exceeding 20 years or to both such fine and imprisonment. ${ }^{[9]}$ They may also be faced with common law action by the children concerned for damages based on a breach of the Act, resulting in unlawful conduct. In addition, doctors may be liable to disciplinary proceedings by the Health Professions Council of South Africa (HPCSA) for unethical and unprofessional conduct.

The Act goes on to state that circumcision of male children older than 16 years may only be performed:

- if the child has given consent to the circumcision in the prescribed manner

- after proper counselling of the child

- in the manner prescribed. ${ }^{[10]}$

No penalties are provided for contravening this section but anyone, including doctors, who undertakes such procedures could face a common law civil action for damages from the circumcised child for breaching the provisions of the Children's Act. Doctors could also be subjected to a disciplinary hearing by the HPCSA for unprofessional conduct.

Finally, the Act states that every male child has the right to refuse circumcision, taking into consideration the child's age, maturity and stage of development. ${ }^{[11]}$ Parents may not override the child's right to refuse circumcision. ${ }^{\left[{ }^{[}\right]}$

\section{Is the mass circumcision of neonates and males a revived Zulu cultural practice?}

If the mass circumcision of all males is done as a revival of the Zulu cultural practice that dates back to before the 19th century, ${ }^{[12]}$ it may, in terms of the Children's Act, only be performed on males older than 16 years and with their consent. ${ }^{[10]}$ Parents, traditional leaders or anyone else may not compel such males to undergo circumcision for cultural reasons. ${ }^{[5]}$ Compulsion to undergo 
circumcision in these circumstances would be illegal and contrary to both the Constitution ${ }^{[13]}$ and the Children's Act ${ }^{[4]}$ - irrespective of whether it is believed that cultural practices should supersede legislation. Cultural practices that conflict with the Constitution will be declared unconstitutional by the courts ${ }^{[5]}$ and those that contravene the Children's Act will be criminal. ${ }^{[9]}$ Violations of either or both may result in criminal and civil actions against the perpetrators.

Can the circumcision of neonates be regarded as a cultural practice? It is trite that cultural circumcision ceremonies are 'rites of passage' whereby boys are initiated into manhood and instructed in the ways of their culture. ${ }^{[12]}$ The circumcision of neonates clearly does not fulfil this function. Even if circumcision were a revived cultural practice for Zulu males, parents would have to wait until their sons are 16 years of age and able to consent to this cultural practice ${ }^{[4]}$ before encouraging them to be circumcised.

\section{Is the mass circumcision of Zulu neonates and males for medical reasons?}

Ethically, and legally, doctors may not engage in futile or worthless medical procedures. ${ }^{[14]}$ Is the mass circumcision of neonates and males being done for medical reasons? The circumcision of male neonates is not a routine practice in most hospitals and healthcare facilities. In the modern world, neonates will only be circumcised for religious or medical reasons, as is provided for in South Africa by the Children's Act. ${ }^{[8]}$ Health-related circumcision will only be carried out if there are good medical reasons for doing so, without which it is a gross violation of human rights. ${ }^{[5]}$ It is likely that when today's neonates are old enough to engage in penetrative sexual activity, there may well be a vaccine against HIV infection. Furthermore, even if a vaccine has not been developed by the time these neonates engage in sexual activity, they would in all likelihood still be warned to use condoms rather than rely on circumcision for protection. Therefore, it could be argued that subjecting neonates to the pain and suffering of an unneccesary circumcision amounts to exposing them to maltreatment, neglect, abuse or degradation, which are outlawed by the Constitution. ${ }^{[15]}$ Such a circumcision also violates the Constitutional requirement of placing the 'best interests' of the child as paramount. ${ }^{[]]}$

The same argument may be applied to boys and adults wishing to be circumcised as protection against HIV infection. The use of condoms is still the best available method of protection against HIV infection, ${ }^{[16]}$ even if males are circumcised, they are advised to continue using condoms for protection. ${ }^{[17]}$ The circumcision drive may risk encouraging failure to use condoms, with resultant undermining of the official campaign urging people to do so. ${ }^{[18]}$ This risks, moreover, negating any medical reason for promoting circumcision if it leads to reversal in the gains made against HIV infection through increased condom use.

\section{What should doctors do?}

When faced with Zulu parents who request that their neonate or boy under the age of 16 years be circumcised for cultural reasons to comply with the King's edict, doctors should inform parents that it would be illegal for them to comply with such a request as this would be against the Children's Act. Doctors should also explain that, until the child reaches the age of 16 years and is able to consent to circumcision for cultural reasons, neither they nor traditional healers are legally permitted to undertake the circumcision.

When faced with parents requesting that their neonate or boy under 16 years be circumcised for medical reasons to reduce the risk of HIV infection, doctors should be satisfied that there are medical grounds for carrying out the procedure. Doctors should inform the parents that when their child is old enough to engage in penetrative sexual activity, there may well be a vaccine against HIV infection. They should state that they are unable to perform the procedure on the neonate or boy unless there is a valid medical reason for circumcision and that the parents should rather wait until the child is legally old enough to decide for himself whether he wishes to be circumcised. Doctors should also explain that, until a vaccine has been developed, all circumcised males will be counselled not to rely on their circumcision as this is not the best protection against HIV infection, but to continue using condoms.

Doctors should be aware that, if they breach the Constitution and the Children's Act, they risk being prosecuted criminally by the state, sued civilly for damages by the person circumcised, and disciplined by the HPCSA.

\footnotetext{
1. South Africa: Zulu King revives male circumcision. http://www.plusnews.org/Report/87441/SOUTH AFRICA-Zulu-king-revives-male-circumcision (accessed 14 January 2013).

2. Statement: KZN Health MEC responds to TAC's criticism over use of device. http://www.hst.org.za/ publications/statement-kzn-health-mec-responds-tac-criticism-over-use -device (accessed 14 January 2013).

3. Section 28 of the Constitution of the Republic of South Africa, 1996

4. Sections 12(8) and (9) of the Children's Act No. 38 of 2005.

5. Justice Alliance of South Africa and Bonani Yamani v Lindile Yamani, Eastern Cape House of Traditional Leaders Chairperson, Eastern Cape CONTRALESA Chairperson, MEC for Health EC and MEC for Local Government, Housing and Traditional Affairs, EC, 2009. Case No. 1/2008, Equality Court, Eastern Cape High Court (Bisho).

6. Section 28(1)(c) and (d) of the Constitution of the Republic of South Africa, 1996

7. Section 28(2) of the Constitution of the Republic of South Africa, 1996.

8. Section 12(8) of the Children's Act No. 38 of 2005

9. Section 305(1)(a) of the Children's Act No. 38 of 2005

10. Section 12(9) of the Children's Act No. 38 of 2005.

1. Section 12(10) of the Children's Act No. 38 of 2005

12. Zulu men and circumcision in South Africa. http://wiki ulwazi.org/index php5?title-Zulu_men_and Circumcision_in_South_Africa (accessed 14 January 2013).

3. Section 12(2) of the Constitution of the Republic of South Africa, 1996

14. Cf. Airedale NHS Trust v Bland [1993] 1 All ER 821.

15. Section $28(1)$ (d) of the Constitution of the Republic of South Africa, 1996

16. Condoms and HIV prevention: Position statement by UNAIDS, UNFPA and WHO, 19 March 2009 http://www.unaids.org/en/resources/presscentre/featurestories/2009/march/20090319preventionposi tion/ (accessed 14 January 2013).

17. Circumcision campaign launched with resounding success. http.//wwwinfo gov za/speech/DynamicA ction?pageid $=4618$ sid $=96898$ tid $=9706$ (accessed 14 January 2013 ).

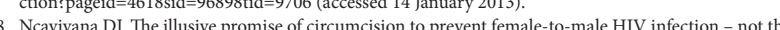
way to go for South Africa S Afr Med J 2011;101:775-776.
}

Accepted 22 January 2013. 